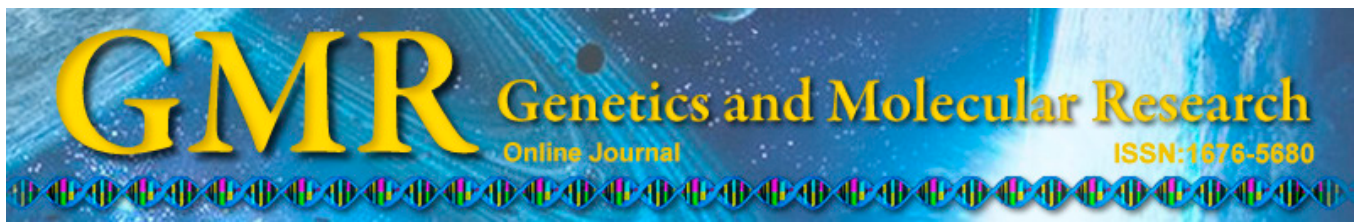

\title{
Correlation of genetic variation among wild Trigonella foenum-graecum L. accessions with their antioxidant potential status
}

\author{
E.A. Haliem ${ }^{1,2}$ and A.A. Al-Huqail ${ }^{1}$ \\ ${ }^{1}$ Department of Botany and Microbiology, Faculty of Science, \\ King Saud University, Riyadh, Saudi Arabia \\ ${ }^{2}$ Department of Botany, Faculty of Science, Zagazig University, Sharkia, Egypt \\ Corresponding author: E.A. Haliem \\ E-mail: ekram@ksu.edu.sa
}

Genet. Mol. Res. 13 (4): 10464-10481 (2014)

Received February 20, 2014

Accepted June 6, 2014

Published December 12, 2014

DOI http://dx.doi.org/10.4238/2014.December.12.8

\begin{abstract}
In this study, we analyzed the correlation between genetic variation based on random amplified polymorphic DNA (RAPD), acid phosphatase, and glutamate-oxaloacetate transaminase isozymes, and amino acid composition with the antioxidant potential status of 7 wild Trigonella foenum-graecum L. accessions collected from diverse ecogeographical regions. RAPD revealed that 90 DNA products had highly polymorphism value $(94.12 \%)$ based on band numbers, with sizes ranging from 50-2100 base pairs, and band intensity. Of 49 DNA polymorphic bands, 31 unique and 3 monomorphic bands were scored. Acid phosphatase and glutamate-oxaloacetate transaminase showed total polymorphism values of 90.00 and $93.75 \%$, respectively, based on zymogram number, relative front $\left(\mathrm{R}_{\mathrm{f}}\right)$, and optical intensity. Because isozymes are composed of amino acids, they were analyzed using highperformance liquid chromatography, which revealed the presences of 16 amino acids of variable content ranging from $13.21-15.35 \%, 9$ of which are essential amino acids in humans. RAPD and isozymes showed similarly high estimates of genetic variability. Genetic relationships
\end{abstract}


revealed by unweighted pair group method with arithmetic mean clustering analysis based on data obtained from all primers of RAPD and each isozyme were very similar. The antioxidant potential based on free radical scavenging, 2, 2-diphenyl-1-picrylhydrazyl, $\beta$-carotenelinoleate, total phenolic, and flavonoid contents values were variable among accessions. We found that fenugreek is a valuable genetic resource with high antioxidant activity. Their genotypes, based on data and clustering of RAPD, isozymes, and variable amino acid contents, combined with their antioxidant potential statues are important in fenugreek breeding and improvement programs.

Key words: Amino acids; Antioxidant potential; Cluster analysis; Isozymes; Random amplified polymorphic DNA;

Trigonella foenum-graecum $\mathrm{L}$.

\section{INTRODUCTION}

Genetic variations between plant materials result from variations in DNA sequences and ecological affects. The assessment and maintenance of genetic variation, which involves the use of biochemical and molecular markers, is crucial for providing a repository of adaptability to environmental stress (Mondini et al., 2009). Several efficient genetic markers are used to reveal genetic variability within and among the same set of plant samples, including random amplified polymorphic DNA (RAPD)-based polymerase chain reaction (PCR), a DNA marker, and isozymes, protein markers. These markers differ from each other with respect to genomic abundance, level of polymorphism detected, locus specificity, reproducibility, technical requirements, cost, and the type of data generated (Gonçalves et al., 2008; Kumar et al., 2009).

DNA markers are independent markers that segregate as single genes; their environmental stability make them ideal tools for studying plants (Kumar et al., 2009). They are used in several techniques, including RAPD-PCR, which is a fast technique for revealing genetic variation and reflecting underlying genetic diversity (Gonçalves et al., 2008). This method requires no prior information regarding the DNA sequence to be amplified (Mondini et al., 2009). RAPD is the simplest DNA-based marker technique, the least time consuming, and can yield a large number of loci, thereby providing a more representative sample of the genome (Mondini et al., 2009). DNA polymorphism identified by RAPD-PCR using single primers of an arbitrary nucleotide sequence can be used to amplify products of random DNA segments (Welsh and McClelland, 1991). RAPD analysis is a multilocus arbitrary fingerprinting technique used to determine genetic relationships in various species (Sadder and Ateyyeh, 2006) and has been used to determine the components of herbal medicinal mixtures (Shinde et al., 2007). Previous studies evaluated genetic diversity among Trigonella foenum-graecum using different DNA genetic markers such as RAPD (Dangi et al., 2004; Harish et al., 2011; Sundaram and Purwar, 2011).

In contrast, isozymes arise from multiple gene loci coding for structurally distinct polypeptide chains. Multiple molecular forms of enzymes show the same substrate specificity but differ in molecular weight, electric charge, or electrophoretic mobility (Karaca, 2013). These differences in size and charge can result from amino-acid substitutions or posttranslational modifications to the enzyme molecules. Protein variants in isozyme analysis are dis- 
tinguished by gel electrophoresis and visualized using an enzyme-specific staining mixture, which includes a substrate, co-factor, and oxidized salt (Karaca, 2013). Previous studies reported that different forms of an enzyme molecule can be separated chemically using electrophoresis to result in different banding patterns and electrophoretic mobilities. Electrophoretic isozyme characteristics are very useful for identifying several levels of taxa, accessions, individuals, genetic variability, phylogenetic systematic information at intrageneric and specific levels, narrow linkage between geography, spatial patterns of genetic variation, and gene expression changes in different developmental and differentiation stages (Dibyendu, 2010; Karaca, 2013). Isozymes are an important dimension in the study of enzymology, biochemistry, cell biology, and genetics, as their analyses are widely applicable, cost-efficient, and relatively rapid (Karaca, 2013). Isozymes are proteins and are thus composed of amino acids; their net electric charge depends on the amino acids present. The different proteins that make up a set of isozymes can catalyze the same reaction, but differ in their kinetics, substrate affinity, number of subunits, and amino acid sequences (Karaca, 2013).

Trigonella foenum-graecum L. (fenugreek) is annual herb in the family Fabaceae (Leguminosae), which grows worldwide. It has a broad spectrum of therapeutic properties such as carminative, tonic, and aphrodisiac effects; it is also useful in diabetes treatment because it contains the amino acid, hydroxyisoleucine, which stimulates the pancreas to release insulin, lowering blood sugar levels (Jha and Srivastava, 2012). Trigonella foenum-graecum seeds are used in many Asian countries as a spice in food preparations because of their strong flavor and therapeutic and medicinal properties. The seeds have also been shown to inhibit cancerous cells of the liver and decrease blood cholesterol level (Sheikhlar, 2013). Because of its strong antioxidant properties, it is a principal ingredient in Ayurvedic formulations (Jha and Srivastava, 2012). Supplementation of fenugreek seed powder in the diet reduces biomarkers of oxidative damage that lead to aging and disease.

Free radicals are generated following environmental genotoxic stresses and cause depletion of immune system antioxidants, the formation of DNA lesions by interacting with DNA. Reactive oxygen species (ROS) are also generated, such as hydroxyl radical ( $\left.{ }^{\circ} \mathrm{OH}\right)$, damaging both the purine and pyrimidine bases, the deoxyribose backbone, changes in gene expression, and abnormal oxidative proteins, leading to mutagenesis, carcinogenesis, and aging (Sanghera et al., 2013). The therapeutic potential of medicinal plants as antioxidant defense machinery for reducing such free radical-induced tissue injury has been increasingly examined. Antioxidant activities of plants have been evaluated using different assay systems to assess free radical scavenging, including hydroxyl radicals/hydrogen peroxide/2, 2-diphenyl-1-picrylhydrazyl (DPPH) radical scavenging and inhibition of lipid peroxidation using the $\beta$-carotene-linoleate model system (Ravindran et al., 2012). The DPPH stable free radical method is an easy, rapid, and sensitive technique for surveying the antioxidant activity of a specific compound or plant extract. $\beta$-carotene protects against oxidative damage and chronic diseases such as cancer (Ravindran et al., 2012). Additionally, the effects of dietary phenolics are currently of great interest because of their antioxidative and potential anticarcinogenic activities, while flavonoids are a group of polyphenolic compounds with known properties, including free radical scavenging, inhibition of hydrolytic, oxidative enzymes, and anti-inflammatory action (Ayala-Zavala et al., 2012). The position and number of hydroxyl groups in the phenolics and flavonoids determine the capacity of the molecules to donate an electron to stabilize free radicals (Ayala-Zavala et al., 2012).

There have been no previous studies estimating the genetic variation and genetic 
structure of Trigonella foenum-graecum using both isozymes and RAPD; thus, the current study used these 2 markers to examine the relative merits of these markers, particularly in highly diverse ecogeographical regions of fenugreek germplasm accessions. Because $T$. foenum-graecum seeds have been reported to exhibit antioxidant activity (Bukhari et al., 2008; Saxena et al., 2011), we examined the correlation between the antioxidant potential of 7 fenugreek accessions with genetic variations based on RAPD molecular markers and biochemical analyses of isozymes and free amino acids to determine how and to what extent each fenugreek accession interacts with environmental genotoxic stress in their natural habitats.

\section{MATERIAL AND METHODS}

\section{Plant materials}

Seeds of 7 accessions of wild T. foenum-graecum were obtained from the repository of seed bank at King Abdul-Aziz City for Science and Technology, Saudi Arabia. Plants used in this investigation were collected from diverse ecogeographical regions in Saudi Arabia and Yemen (Table 1). Viable seeds were sterilized, screened for size uniformity, and divided into 4 groups for RAPD, isozyme, amino acids, and antioxidant analyses. Seeds were used rather than leaves for these analyses to enable accurate estimation in species with reduced leaves or leaves that accumulate staining inhibitors, as well as for species growing in regions in which these techniques are not readily available (Sliwinska et al., 2009).

\begin{tabular}{lcc} 
Table 1. List of Trigonella foenum-graecum accessions used in the present study and their origins. \\
\hline No. & Accessions & Origin \\
\hline 1 & 12 & Saudi Arabia \\
2 & 50 & Yemen \\
3 & 51 & Yemen \\
4 & 74 & Saudi Arabia \\
5 & 98 & Yemen \\
6 & 122 & Saudi Arabia \\
7 & 136 & Saudi Arabia \\
\hline
\end{tabular}

\section{DNA-marker analysis using RAPD-PCR}

\section{Isolation of genomic DNA}

Genomic DNA from fenugreek seeds was extracted using the hexadecyl trimethyl ammonium bromide method as described by Kit and Chandran (2010).

\section{Qualitative and quantitative analyses of extracted DNA}

DNA yield was measured using a UV-visible spectrophotometer (PerkinElmer, Waltham, MA, USA) at $260 \mathrm{~nm}$. DNA purity was determined by calculating the absorbance ratio at $\mathrm{A}_{260 / 280} \mathrm{~nm}$. Polysaccharide contamination was assessed by calculating the absorbance ratio at $\mathrm{A}_{260 / 230} \mathrm{~nm}$ (Wilson and Walker, 2005). For quality and yield assessments, electrophoresis was performed for all DNA samples on $0.8 \%$ agarose gels that were stained with ethidium bromide; the bands were observed using a gel documentation system (AlphaInnotech, San 
Leandro, CA, USA) and compared with a known standard lambda DNA marker sample.

\section{PCR amplification using random primers of $R A P D$}

The PCR reaction mixture contained $2.5 \mu \mathrm{L} 10 \mathrm{X}$ buffer with $15 \mathrm{mM} \mathrm{MgCl}_{2}$ (Fermentas, Vinius, Lithuania), with $0.25 \mathrm{mM}$ of each dNTP (Sigma, St. Louis, MO, USA), $0.3 \mu \mathrm{M}$ primer, 0.5 U Taq DNA polymerase (Sigma), and 50 ng template DNA. The PCR was performed in a Palm Cycler apparatus (Corbett Research) using the following method: initial denaturation of $4 \mathrm{~min}$ at $95^{\circ} \mathrm{C}$ followed by 40 cycles of $1 \mathrm{~min}$ at $95^{\circ} \mathrm{C}, 1 \mathrm{~min}$ at $38^{\circ} \mathrm{C}$, and $2 \mathrm{~min}$ at $72^{\circ} \mathrm{C}$ with final extension at $72^{\circ} \mathrm{C}$ for $10 \mathrm{~min}$ and a hold temperature of $4^{\circ} \mathrm{C}$. A total of 20 random DNA oligonucleotide primers (10-mer) were independently used in the PCRs (University of British Columbia, Canada) according to Williams et al. (1990) with some modifications. Only 5 primers (A-01, 02, 04, 06, and 08) successfully generated reproducible DNA amplification products. For DNA amplification, the PCR was run for 35 cycles, which consisted of a denaturation step (1 min at $\left.95^{\circ} \mathrm{C}\right)$, annealing step $\left(1 \mathrm{~min}\right.$ at $\left.35^{\circ} \mathrm{C}\right)$, and elongation step $\left(2 \mathrm{~min}\right.$ at $\left.72^{\circ} \mathrm{C}\right)$. After 34 cycles, a final extension period was added $\left(5 \mathrm{~min}\right.$ at $\left.72^{\circ} \mathrm{C}\right)$. Amplification products were electrophoresed on $1.5 \%$ agarose gel (Sigma) in TAE buffer $(0.04 \mathrm{M}$ Tris-acetate, $1 \mathrm{mM}$ EDTA, $\mathrm{pH}$ 8). The gel was run at $100 \mathrm{~V}$ constant voltage for $1 \mathrm{~h}$. Gels were stained with $0.2 \mu \mathrm{g} / \mathrm{mL}$ ethidium bromide for $15 \mathrm{~min}$. The PCR products were visualized under a UV light transilluminator. The 100-base pair DNA ladder (Gibco-BRL, Grand Island, NY, USA) was loaded into the first lane of each gel to evaluate band sizes. The gels were photographed under UV light using a gel documentation system (Bio-Rad, Hercules, CA, USA).

\section{Scoring and data analyses}

After separating PCR products by agarose gel electrophoresis, the gels were visualized using a Photo Print (Vilber Lourmat, France) imaging system. Quantitative variations in band numbers and band sizes as well as band intensity were analyzed using the Bio-One $\mathrm{D}++$ software (Vilber Lourmat, France). Data were scored as the presence or absence of DNA bands.

\section{Unweighted pair group method with arithmetic mean (UPGMA) clustering dendrogram analysis}

The PAST computer program (dendrogram window) was used for UPGMA clustering analysis using simple band match (tolerance $3.20 \%$ ) to determine the genetic relationships among the fenugreek accessions based on the data of the 5 primers used for RAPD analysis. The presence or absence of DNA bands, as well as the sizes, the numbers, and band intensities, were used to estimate the genetic relationships in the dendrogram.

\section{Biochemical analysis of isozymes}

Two isozymes, acid phosphatase (ACP) and glutamate-oxaloacetate transaminase (GOT), were used in this experiment. Viable, cleaned, and sterilized seeds of the different fenugreek accessions were separately milled and defatted according to methods described by Hojilla-Evangelista and Evangelista (2006). Approximately 0.4 g powdered seed was homogenized with acid-washed sand and $400 \mathrm{~mL}$ extraction buffer. Extraction buffer consisted of $0.1 \mathrm{M}$ 
Tris- $\mathrm{HCl}$ (pH 7.5) containing 20\% sucrose as described by Majumder et al. (2012). The samples were then centrifuged at $15,000 \mathrm{~g}$ for $15 \mathrm{~min}$ at $4{ }^{\circ} \mathrm{C}$; the supernatant was collected for isozyme analyses in a separate vial. Each sample was applied to vertical polyacrylamide gel electrophoresis (4.5\% stacking, $9 \%$ separating gel) using a mini gel apparatus in Tris-glycine ( $\mathrm{pH} 8.3$ ) buffer as described by Majumder et al. (2012). The gels were stained for ACP and GOT separately with specific staining solutions as described by Pasteur et al. (1988) and Solties et al. (1983), respectively. Gels were photographed using the Vilber Lourmat gel documentation system.

\section{Gel scoring and data analyses}

The isozymatic banding patterns observed after enzyme electrophoresis were compared among the different accessions based on zymogram number, their relative front $\left(\mathrm{R}_{\mathrm{f}}\right)$ values on gel electrophoresis, and their intensities. The $\mathrm{R}_{\mathrm{f}}$ value was the mobility of each isozyme band that traveled from the origin divided by the distance traveled by the tracking dye. Data were scored as the presence or absence of zymogram of a unique pattern.

\section{UPGMA clustering dendrogram analysis}

The PAST computer program (dendrogram window) was used for the UPGMA clustering analysis using simple band matching (tolerance, 3.20\%) to indicate the genetic relationships among fenugreek accessions, based on the data obtained from GOT and ACP isozyme separately for the variable number zymograms, $R_{f}$ values, and intensities. Zymograms were drawn to scale and relative mobility values were calculated for each band.

\section{Biochemical analysis of amino acids composition using high-performance liquid chromatography (HPLC)}

Free amino acids (AAs) were extracted from raw seed fine powders of studied fenugreek accessions as described by Aly et al. (2011) with some modifications. Amino acid analyses were performed by HPLC after hydrolysis of samples with $6 \mathrm{~N} \mathrm{HCl}$ at $110^{\circ} \mathrm{C}$ under vacuum for $24 \mathrm{~h}$ on an amino acid analyzer (Applied Biosystems 421 amino acid analyzer, Foster City, CA, USA) as described by Pirman et al. (2001). The results of the analysis were expressed as the nitrogen $(\mathrm{N})$ content of the sample: $\mathrm{g} / 100 \mathrm{~g}$ of crude protein $(\mathrm{N} \times 6.25)$. The quality of amino acid composition was tested using the essential amino acid index (EAAI) and the amino acids were quantified by comparing the peak area with corresponding amino acid standard solutions using the Spectra Physics Data System program (Santa Clara, CA, USA).

\section{Antioxidant potential assays}

Powdered fenugreek seeds of each accession were extracted using methanol solvents by soxhelt extraction for $6 \mathrm{~h}$ according to Lim et al. (2002). The extracts were combined, filtered, and evaporated to dryness under reduced pressure at $60^{\circ} \mathrm{C}$ in a rotary evaporator. Extracts were placed in dark bottle and stored at $-8^{\circ} \mathrm{C}$ until further analyses. The antioxidant potential in fenugreek seeds was analyzed by various in vitro assay systems, a 2, 2-diphenyl1 -picrylhydrazyl scavenging assay, free radical scavenging, $\beta$-carotene-linoleate model system, total phenolic, and flavonoid contents. 


\section{DPPH radical-scavenging activity}

DPPH radical-scavenging activity, antioxidant activity of the samples, and standards were determined by the radical scavenging activity method using DPPH in triplicate according to Gil et al. (2000). Absorbance (Abs) was measured at $\lambda=517 \mathrm{~nm}$. Radical scavenging activity was expressed at the inhibition percentage and was calculated using the following equation:

$$
\% \text { DPPH radical }- \text { scavenging activity }=\frac{\text { control Abs }- \text { sample Abs }}{\text { control Abs }} \times 100 \quad \text { (Equation 1) }
$$

\section{B-carotene-linoleate model system}

The antioxidant activity of seed extract was also evaluated by the $\beta$-carotene-linoleate model system as inhibition of lipid peroxidation based on the procedure described by Miller (1993). Antioxidant activity was calculated using the following equation:

$$
\% \text { Antioxidant activity }=\frac{\beta-\text { carotene content after } 2 \mathrm{~h}}{\beta-\text { carotene content at initial stages }} \times 100 \quad \text { (Equation 2) }
$$

\section{Total phenolic and flavonoid contents}

Total phenolic and flavonoid content were determined using the Folin-Ciocalteu and aluminum chloride methods, respectively. Total soluble phenolic content was estimated for each extract following the method of Ravindran and Naveenan (2011). Gallic acid was used as the phenolic standard. The concentration of total phenol compounds was calculated using a standard curve of gallic acid equivalents and expressed as $\mu \mathrm{g}$ per mg dry weight. Flavonoid content was determined based on the methods described by Zhishen et al. (1999) with some modifications. The results were expressed as $\mu \mathrm{g}$ quercetin equivalents per mg dry weight.

\section{Data and UPGMA clustering dendrogram analyses}

Three replicates $(\mathrm{N}=3)$ of each sample were used for statistical analysis. Data were reported as means \pm standard deviation. The PAST computer program (dendrogram window) was used for UPGMA clustering analysis using simple band match (tolerance, 3.20\%) to indicate relationships among fenugreek accessions based on the antioxidant activity data obtained.

\section{RESULTS}

\section{DNA-marker analysis using RAPD}

\section{Survey of RAPD polymorphisms}

Estimation of genetic variation is very important for crop improvement programs. 
In the current study, we examined the level of genetic variation among 7 T. foenum-graecum accessions using RAPD analysis. The code and sequences of the 5 RAPD primers (A-01, 02, 04, 06, and 08) were listed in (Table 2). A total of 96 amplified DNA products were scored; these bands varied in specific random sequences, band intensity, and sizes, ranging from 50$2100 \mathrm{bp}$. An average of 18.20 bands per primer was scored. RAPD analysis generated highly polymorphism values of 94.44 and $53.13 \%$ (51 in total) DNA polymorphic bands, of which 32 were unique and 3 were monomorphic bands. Primer- 06 produced the maximum number of unique bands, 11 with a value of $57.89 \%$, while Primer-08 had the highest number of nonunique bands, 6 with a value of $27.27 \%$. However, Primer- 01 and 04 only revealed 2 and 1 monomorphic bands, respectively. Furthermore, the maximum number of bands was 17, with a value $17.71 \%$ scored in fenugreek A-50, while A-98 and A-136 scored 12 bands with value $12.5 \%$. Furthermore, Primer-02 and Primer-01 amplified the lowest number of bands, including 15 bands with a value $15.63 \%$, and the highest number of bands, including 23 bands with a value of $23.96 \%$, respectively. Primers- 02,06 , and 08 generated $100 \%$ polymorphisms, while primers- 01 and 04 revealed 80.00 and $85.71 \%$ polymorphisms, respectively, based on the absence or presence of monomorphic bands (Table 2 and Figure 1).

\section{UPGMA clustering dendrogram based on RAPD analysis}

The UPGMA clustering dendrogram based on RAPD analysis showed 2 major clusters from the RAPD data (Figure 2). Cluster I comprised fenugreek A-50, which was completely separated from the other 6 accessions in the second cluster, with a genetic relationship ratio of $33.45 \%$. Cluster II was divided into 2 sub-clusters, i and ii, with a genetic relationship ratio of $61.78 \%$. Sub-cluster i included 2 groups, 1 and 2, with a genetic relationship ratio of $72.02 \%$. Group 1 contained clades A-12 and A-22, with a genetic relationship ratio of $76.92 \%$. Group 2 contained clades A-136 and A-98, with a genetic relationship ratio of $94.74 \%$. In contrast, sub-cluster ii included A-51 and A-74, with a genetic relationship ratio of $82.35 \%$. Based on these results, 2 accessions, 98 and 136, were very closely related, according to their highly similar polymorphism values.

\section{Isozyme analysis}

\section{Survey of electrophoretic isozyme polymorphisms}

The GOT and ACP isozymes used in the present study showed clear polymorphisms among accessions based on the number of zymograms, the $\mathrm{R}_{\mathrm{f}}$ values, and their optical intensities (Table 3 and 4; Figure 3A and B). A total of 81 different electrophoretic zymograms were observed for the 2 isozymes. GOT and ACP analyses generated 52 and 27 zymograms, respectively, with different $R_{f}$ values ranging from 0.17-0.97 for GOT and 0.09-0.89 for ACP. GOT analysis revealed 15 polymorphic zymograms (4 unique and 11 non-unique zymograms) and 1 monomorphic zymogram. These zymograms generated a high value of polymorphism of $93.75 \%$, while ACP analysis revealed 9 polymorphic zymograms (4 unique and 5 nonunique zymograms) and 1 monomorphic zymogram with a considerable polymorphism value of $90.00 \%$. GOT and ACP analyses generated higher numbers of zymograms for accession A-50, including 10 zymograms with a value of $18.52 \%$ and 7 zymograms with a value of $25.93 \%$ of total bands for the 2 isozymes, respectively. 
E.A. Haliem et al.

10472

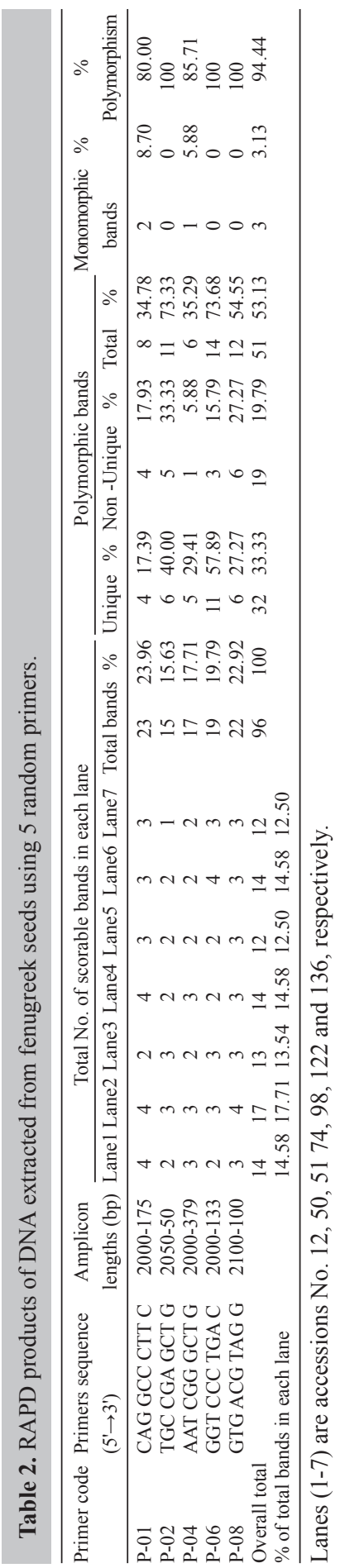

Genetics and Molecular Research 13 (4): 10464-10481 (2014)

CFUNPEC-RP www.funpecrp.com.br 

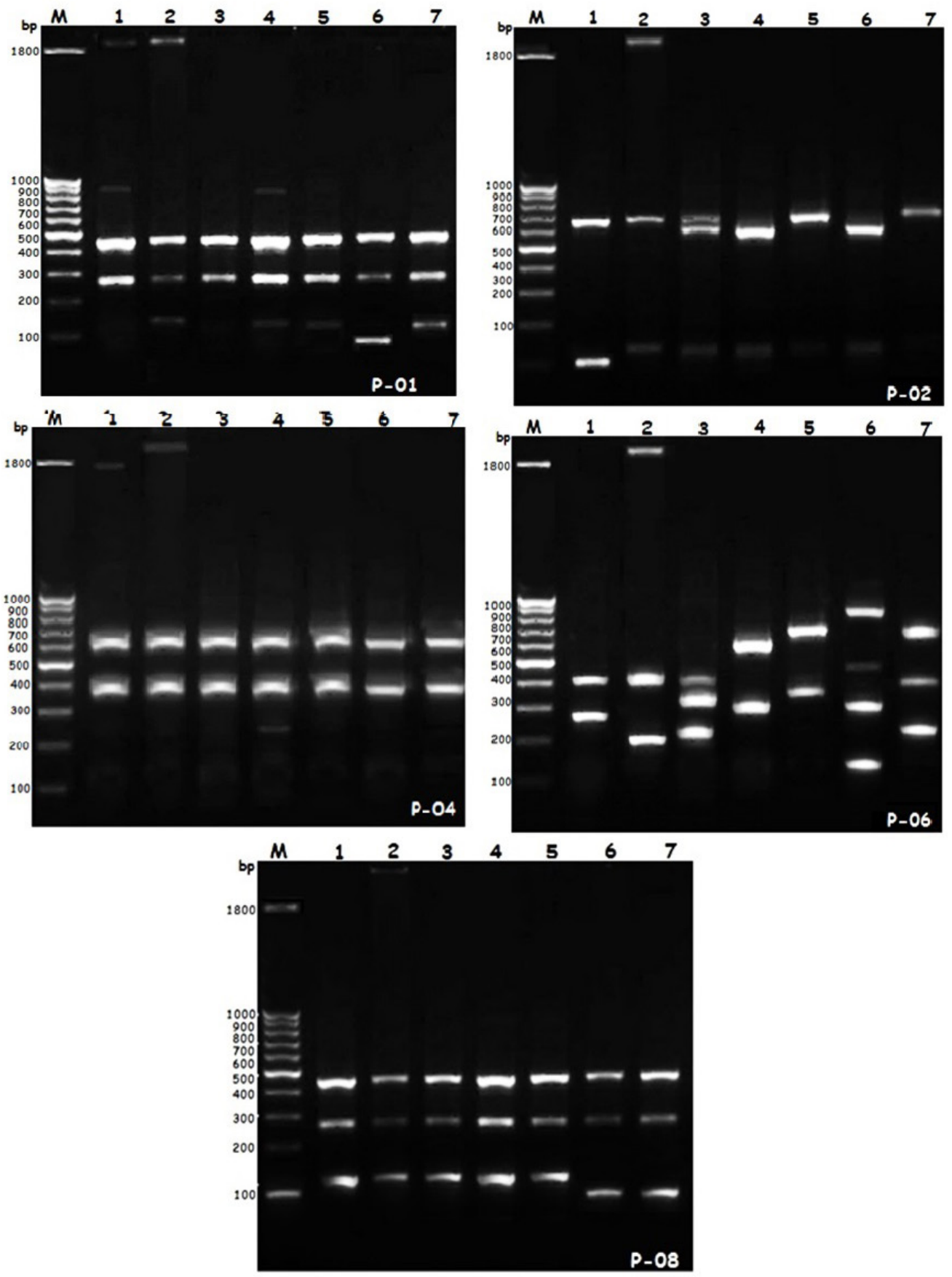

Figure 1. RAPD products of DNA fragments extracted from seeds of fenugreek accessions using 5 primers (P-01, 02, 04, 06, and 08). Lane $M=100$-bp DNA marker. Lanes 1-7 = germplasm accessions (A-12, A-50, A-51, A-74, A-98, A-122, and A-136), respectively. 


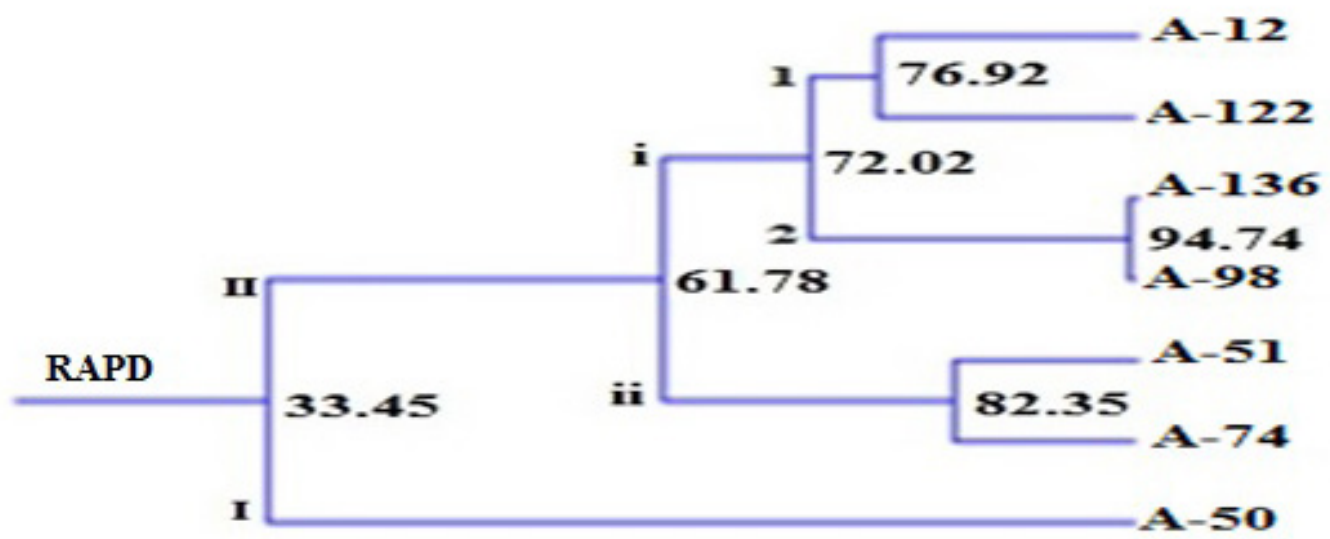

Figure 2. Dendrogram representing genetic relationship between studied fenugreek accessions as determined through UPGMA clustering using simple band matches (tolerance, 3.20\%) based on all primers in the RAPD database analysis.

Table 3. Distribution of glutamate-oxaloacetate transaminase (GOT) zymograms among fenugreek accessions.

\begin{tabular}{|c|c|c|c|c|c|c|c|c|c|c|c|c|c|c|}
\hline \multirow[t]{2}{*}{ Rows } & \multirow[t]{2}{*}{ RF value } & \multicolumn{2}{|c|}{ A-12 } & \multicolumn{2}{|c|}{ A-50 } & \multicolumn{2}{|c|}{ A-51 } & \multicolumn{2}{|c|}{ A-74 } & \multicolumn{2}{|c|}{ A-98 } & A-122 & A-136 & \multirow[t]{2}{*}{ Polymorphism types } \\
\hline & & $\mathrm{R}_{\mathrm{f}}$ & OD & $\mathrm{R}_{\mathrm{f}}$ & OD & $\mathrm{R}_{\mathrm{f}}$ & OD & $\mathrm{R}_{\mathrm{f}}$ & OD & $\mathrm{R}_{\mathrm{f}}$ & OD & OD & $\mathrm{R}_{\mathrm{f}} \quad \mathrm{OD}$ & \\
\hline 1 & 0.17 & & & & & $\sqrt{ }$ & 3.56 & $\sqrt{ }$ & 4.67 & & & & & Non-U \\
\hline 2 & 0.19 & & & $\sqrt{ }$ & 2.42 & $\sqrt{ }$ & 2.26 & $\sqrt{ }$ & 8.87 & & & & & Non-U \\
\hline 3 & 0.20 & & & $\sqrt{ }$ & 3.22 & & & & & $\sqrt{ }$ & 2.38 & 5.34 & & Non-U \\
\hline 4 & 0.36 & $\sqrt{ }$ & 16.94 & & & $\sqrt{ }$ & 16.67 & $\sqrt{ }$ & 18.45 & & & & 8.46 & Non-U \\
\hline 5 & 0.44 & $\sqrt{ }$ & 12.34 & $\sqrt{ }$ & 14.78 & $\sqrt{ }$ & 12.56 & $\sqrt{ }$ & 10.43 & $\sqrt{ }$ & 10.86 & $\sqrt{ } \quad 11.28$ & $\sqrt{ } 10.56$ & M \\
\hline 6 & 0.46 & $\sqrt{ }$ & 89.06 & & & & & & & & & & & $\mathrm{U}$ \\
\hline 7 & 0.47 & & & $\sqrt{ }$ & 10.89 & $\sqrt{ }$ & 86.28 & $\sqrt{ }$ & 86.80 & $\sqrt{ }$ & 85.99 & & 8.44 & Non-U \\
\hline 8 & 0.49 & & & $\sqrt{ } 8$ & 83.13 & & & & & $\sqrt{ }$ & 8.56 & $\sqrt{ } \quad 68.11$ & $\sqrt{ } 80.86$ & Non-U \\
\hline 9 & 0.50 & $\sqrt{ }$ & 10.12 & $\sqrt{ }$ & 10.34 & & & $\sqrt{ }$ & 9.56 & $\sqrt{ }$ & 4.67 & $\sqrt{ } \quad 16.94$ & $\sqrt{ } \quad 5.43$ & Non-U \\
\hline 10 & 0.57 & & & $\sqrt{ }$ & 8.45 & $\sqrt{ }$ & 10.67 & & & & & & & Non-U \\
\hline 11 & 0.63 & $\sqrt{ }$ & 5.23 & & & & & & & & & & & $\mathrm{U}$ \\
\hline 12 & 0.69 & & & & & & & & & & & & 3.89 & $\mathrm{U}$ \\
\hline 13 & 0.84 & $\sqrt{ }$ & 3.78 & & & & & $\sqrt{ }$ & 4.34 & $\sqrt{ }$ & 4.43 & 6.44 & 5.93 & Non-U \\
\hline 14 & 0.86 & & & $\sqrt{ }$ & 7.23 & $\sqrt{ }$ & 4.58 & $\sqrt{ }$ & 3.89 & $\sqrt{ }$ & 2.11 & 3.70 & & Non-U \\
\hline 15 & 0.89 & & & $\sqrt{ }$ & 3.12 & $\sqrt{ }$ & 3.48 & $\sqrt{ }$ & 2.90 & & & & 4.76 & Non-U \\
\hline 16 & 0.97 & & & $\sqrt{ }$ & 3.85 & & & & & & & & & U \\
\hline \multicolumn{2}{|c|}{ No. total bands $=54$} & \multirow{2}{*}{\multicolumn{2}{|c|}{$\begin{array}{c}6 \\
11.11 \\
\end{array}$}} & \multirow{2}{*}{\multicolumn{2}{|c|}{$\begin{array}{l}10 \\
18.52\end{array}$}} & \multirow{2}{*}{\multicolumn{2}{|c|}{$\begin{array}{c}8 \\
14.81\end{array}$}} & \multirow{2}{*}{\multicolumn{2}{|c|}{$\begin{array}{c}9 \\
16.67\end{array}$}} & \multirow{2}{*}{\multicolumn{2}{|c|}{$\begin{array}{c}7 \\
12.96 \\
\end{array}$}} & \multirow{2}{*}{$\begin{array}{c}6 \\
11.11\end{array}$} & \multirow{2}{*}{$\begin{array}{c}8 \\
14.81\end{array}$} & \\
\hline Band $\mathrm{fi}$ & ency $(\%)$ & & & & & & & & & & & & & \\
\hline \multirow{3}{*}{\multicolumn{2}{|c|}{$\begin{array}{l}\text { Types and frequency } \\
\text { of isozymatic bands }\end{array}$}} & \multicolumn{2}{|c|}{ Unique $(\mathrm{U})$} & \multicolumn{4}{|c|}{ Non-unique (Non-U) } & \multicolumn{2}{|c|}{ Polymorphic } & & onom & phic (M) & \multirow{3}{*}{\multicolumn{2}{|c|}{$\begin{array}{c}\% \text { of total polymorphism } \\
93.75\end{array}$}} \\
\hline & & No. & $\%$ & $\mathrm{No}$ & & & $\%$ & No. & $\%$ & No & & $\%$ & & \\
\hline & & 4 & 7.41 & 11 & & & 20.37 & 15 & 27.78 & 1 & & 1.85 & & \\
\hline
\end{tabular}

\section{UPGMA clustering dendrogram based on isozyme analysis}

The UPGMA clustering dendrogram based on GOT and ACP isozymes analyses revealed 2 major clusters I and II (Figure 4). The first cluster I of the 2 isozymes included fenugreek accession A-50, which was completely separated from the other 6 accessions in the second cluster II with genetic relationship ratios of 60.52 and $36.67 \%$, respectively. The second cluster II of GOT and ACP was divided into 2 sub-clusters, i and ii, with genetic relationship ratios of 71.44 and $55.45 \%$, respectively. Sub-cluster i of GOT included 2 groups, 1 and 2, with a genetic relationship ratio of $83.04 \%$, while the ACP dendrogram contained 
group 1. Group 1 of GOT and ACP contained 2 clades $(a, b)$, with genetic relationship ratios of 88.89 and $80.00 \%$, respectively. Clade a) of GOT included A-74 and A-51, while that of ACP included A-12 and A-51, with genetic relationship ratios of 90.65 and $75.45 \%$, respectively. In contrast, clade b) of GOT included A-122 and A-98, while that of ACP included A-74 and A-98, with the same genetic relationship ratio of $95.00 \%$. The GOT group 2 included A-136. Furthermore, sub-cluster ii included only A-12 for GOT, while ACT included A-122 and A-136 with a genetic relationship ratio of $97.52 \%$.

Comparison of the clustering pattern on the GOT and ACP isozyme dendrogram revealed that A-50 was completely separated from the other 6 accessions. Additionally, A-122 was closely genetically related to A-98 on the GOT and A-136 on the ACP dendrogram, which may be due to similarity in geographic regions.

Table 4. Distribution of acid phosphatase (ACP) zymograms among fenugreek accessions.

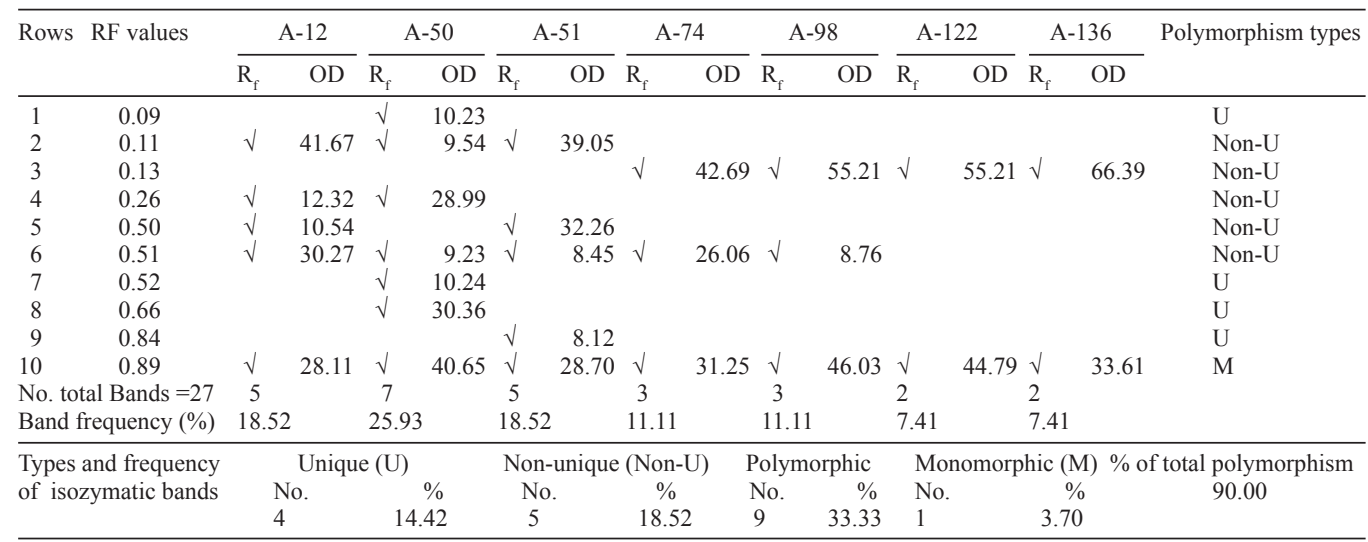

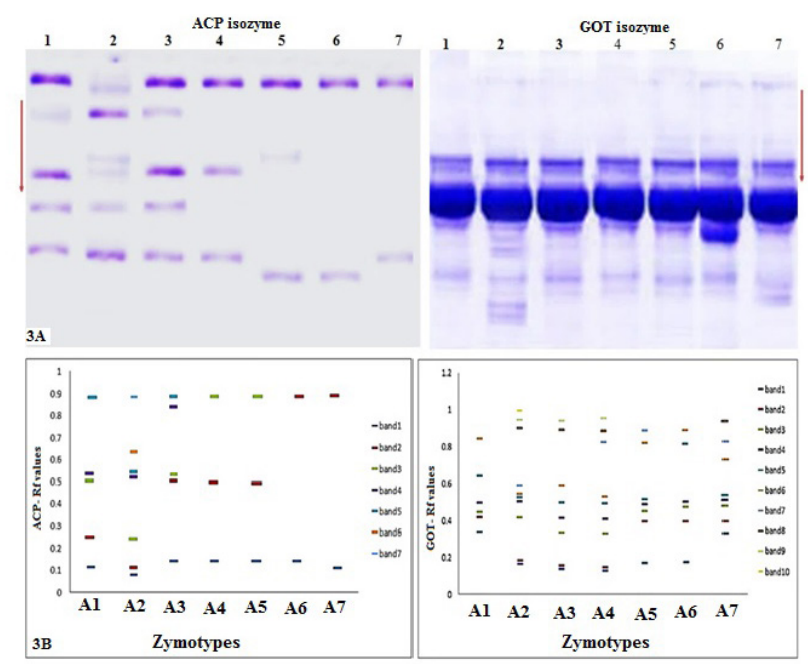

Figure 3. Banding pattern (3A) and schematic distribution (3B) of GOT and ACP zymograms ( $\mathrm{R}_{\mathrm{f}}$ values) in studied fenugreek accessions. Lanes 1-7 = germplasm accessions A-12, A-50, A-51, A-74, A-98, A-122, and A-136, respectively. Arrows indicate the direction of sample migration. 

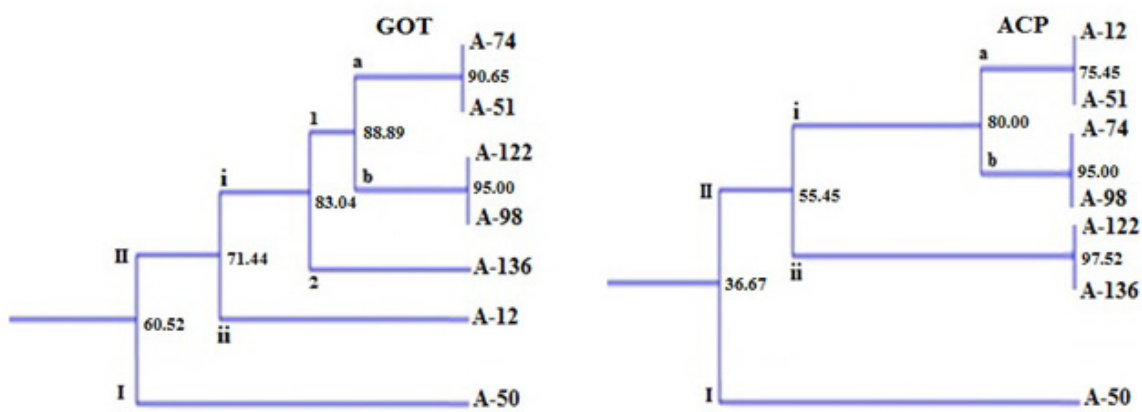

Figure 4. Dendrograms representing genetic relationship between studied fenugreek germplasms accessions determined through UPGMA clustering using simple band matches (tolerance, 3.20\%) based on GOT and ACP database analysis of each sample seperately.

\section{Amino acid analysis}

The results of EAA and non-essential (NEAAs) amino acid compositions of the raw seeds of fenugreek accessions are shown in Table 5. HPLC analysis revealed the presence of 16 amino acids, 9 of which are essential in humans. The highest content of total free amino acids was scored for A-50, while the lowest was for A-136, with values of 15.35 and $13.21 \%$, respectively. Total EAA content (55.83\%) was higher than NEAA (44.17\%) for the total seed protein. Seeds of fenugreek accessions varied in the type of EAAs; valine was prevalent in A-12 and A-98, phenylalanine in A-50 and A-51, threonine in A-74, and lysine in A-122 and A-136, while the NEAA aspartic acid was prevalent in all accessions, except that tyrosine and alanine were rich in A-122 and A-136, respectively. Furthermore, the NEAA aspartic acid scored $10.51 \%$ of the entire amino acids content, while the EAA methionine scored the lowest value of $3.96 \%$.

\begin{tabular}{|c|c|c|c|c|c|c|c|c|c|}
\hline Amino acids ( $\mathrm{g} / 100 \mathrm{~g}$ protein) & A-12 & A-50 & A-51 & A-74 & A-98 & A-122 & A-136 & Total AAs & $\%$ \\
\hline & \multicolumn{9}{|c|}{ Essential amino acids (EAAs) } \\
\hline Arginine & 7.000 & 6.131 & 8.100 & 7.047 & 9.310 & 5.334 & 7.094 & 50.02 & 7.68 \\
\hline Histidine & 3.082 & 5.437 & 5.451 & 7.250 & 4.099 & 4.078 & 3.059 & 32.46 & 4.99 \\
\hline Isoleucine & 6.359 & 4.964 & 4.242 & 5.641 & 5.596 & 3.763 & 5.005 & 35.57 & 5.46 \\
\hline Leucine & 6.547 & 5.446 & 4.665 & 3.536 & 4.963 & 4.128 & 4.541 & 33.83 & 5.20 \\
\hline Lysine & 5.265 & 6.625 & 6.092 & 5.300 & 7.003 & 8.282 & 8.489 & 47.06 & 7.22 \\
\hline Methionine & 2.097 & 4.638 & 2.622 & 3.488 & 2.790 & 4.360 & 5.799 & 25.79 & 3.96 \\
\hline Phenylalanine & 6.883 & 8.583 & 8.605 & 6.454 & 6.470 & 7.210 & 5.407 & 49.61 & 7.62 \\
\hline Threonine & 5.485 & 6.846 & 6.128 & 8.150 & 4.607 & 5.751 & 4.830 & 41.80 & 6.42 \\
\hline Valine & 7.247 & 6.652 & 7.884 & 5.913 & 9.639 & 5.787 & 4.282 & 47.40 & 7.28 \\
\hline Sum & 49.97 & 55.30 & 53.79 & 52.78 & 54.48 & 48.69 & 48.51 & 363.52 & 55.83 \\
\hline \multirow[t]{2}{*}{$\%$} & 13.75 & 15.21 & 4.80 & 14.52 & 15.00 & 13.39 & 13.34 & & \\
\hline & \multicolumn{9}{|c|}{ Non-essential amino acids (NEAAs) } \\
\hline Alanine & 4.733 & 6.296 & 4.722 & 6.280 & 4.710 & 6.264 & 8.331 & 41.34 & 6.35 \\
\hline Aspartic acid & 13.892 & 12.225 & 10.758 & 9.467 & 8.331 & 7.331 & 6.451 & 68.46 & 10.51 \\
\hline Cysteine & 0.158 & 0.210 & 0.280 & 0.372 & 0.495 & 0.659 & 0.876 & 3.05 & 0.47 \\
\hline Glutamic acid & 11.953 & 10.519 & 9.256 & 8.146 & 7.168 & 6.308 & 5.551 & 58.90 & 9.05 \\
\hline Glycine & 4.676 & 6.219 & 5.472 & 4.816 & 6.020 & 4.515 & 3.973 & 35.91 & 5.51 \\
\hline Proline & 3.686 & 4.176 & 3.925 & 4.447 & 5.039 & 5.709 & 5.366 & 32.35 & 4.97 \\
\hline Tyrosine & 3.872 & 5.149 & 6.849 & 9.109 & 6.831 & 9.086 & 6.814 & 47.71 & 7.33 \\
\hline Sum & 42.97 & 44.68 & 41.47 & 42.75 & 38.69 & 39.59 & 37.46 & 287.61 & 44.17 \\
\hline$\%$ & 14.93 & 15.55 & 14.42 & 14.86 & 13.45 & 13.77 & 13.02 & & \\
\hline Total No. of EAAs and non-EAAs & 92.94 & 99.98 & 95.26 & 95.53 & 93.17 & 88.28 & 85.97 & 651.13 & 100 \\
\hline$\%$ & 14.27 & 15.35 & 14.63 & 14.67 & 14.31 & 13.56 & 13.21 & & \\
\hline
\end{tabular}




\section{Antioxidant potential assays}

The antioxidant potential of fenugreek seeds was analyzed employing various in vitro assay systems, including hydroxyl radicals/hydrogen peroxide/DPPH radical scavenging assay and inhibition of lipid peroxidation using the $\beta$-carotene-linoleate model system, in addition to total phenolic and flavonoid contents as shown in (Table 6). Fenugreek A-50 showed the highest DPPH radical scavenging activity, antioxidant activity of $\beta$-carotene-linoleate, and total phenolic content, reaching $57.08 \pm 0.47 \%, 62.51 \pm 2.40 \%$, and $57.04 \pm 0.06 \mu \mathrm{g} / \mathrm{mg}$ respectively. This accession also scored the lowest value of flavonoid content that reached $83.36 \pm 1.60 \mu \mathrm{g} / \mathrm{mg}$. In contrast, A-136 showed the highest flavonoid content of $127.30 \pm 1.12$ $\mu \mathrm{g} / \mathrm{mg}$ and the lowest DPPH radical scavenging activity, antioxidant activity of $\beta$-carotenelinoleate, and total phenolic content, with values of $42.92 \pm 2.1 \%, 51.34 \pm 2.80 \%$, and 49.56 $\pm 0.03 \mu \mathrm{g} / \mathrm{mg}$ respectively.

Table 6. Antioxidant capacity, total phenolics, and flavonoid contents of fenugreek seeds extracts. Values are reported as means \pm standard deviation $(\mathrm{N}=3)$.

\begin{tabular}{lcccc}
\hline Accessions & \multicolumn{3}{c}{ Antioxidant activity parameters } \\
\cline { 2 - 5 } & $\begin{array}{c}\text { \% of DPPH } \\
\text { scavenging }\end{array}$ & $\begin{array}{c}\text { \% of } \beta \text {-carotene } \\
\text { antioxidant activity }\end{array}$ & $\begin{array}{c}\text { Phenol content } \\
(\mathrm{GAE} \mu \mathrm{g} / \mathrm{mg})\end{array}$ & $\begin{array}{r}\text { Flavonoid content } \\
(\mathrm{QE} \mu \mathrm{g} / \mathrm{mg})\end{array}$ \\
\hline A-12 & $54.23 \pm 0.04$ & $56.88 \pm 1.70$ & $55.22 \pm 0.02$ & $102.50 \pm 2.01$ \\
A-50 & $57.08 \pm 0.47$ & $62.51 \pm 2.4$ & $57.04 \pm 0.06$ & $83.36 \pm 1.60$ \\
A-51 & $48.36 \pm 0.21$ & $61.72 \pm 2.30$ & $56.15 \pm 0.03$ & $97.47 \pm 2.30$ \\
A-74 & $44.01 \pm 2.30$ & $54.04 \pm 2.30$ & $53.34 \pm 0.02$ & $103.10 \pm 3.5$ \\
A-98 & $47.21 \pm 3.2$ & $55.63 \pm 3.20$ & $54.52 \pm 0.03$ & $111.30 \pm 1.30$ \\
A-122 & $45.46 \pm 2.1$ & $4.62 \pm 2.10$ & $51.91 \pm 0.04$ & $113.9 \pm 4.20$ \\
A-136 & $42.92 \pm 2.1$ & $51.34 \pm 2.80$ & $49.56 \pm 0.03$ & $127.30 \pm 1.12$ \\
\hline
\end{tabular}

\section{UPGMA clustering dendrogram based on antioxidant potential data}

The UPGMA clustering dendrogram based on the antioxidant activity data showed 2 major clusters I and II with a relationship ratio of $75.84 \%$ (Figure 5). Cluster II was divided into 2 sub-clusters, 1 and 2, with a relationship value of $83.28 \%$. Sub-cluster 1 included A-12 and A-51, showing a relationship ratio of $83.04 \%$, while sub-cluster 1 included A-50. In contrast, cluster I was divided into 2 sub-clusters, 3 and 4, with a relationship value of $80.09 \%$. Sub-cluster 3 included 2 groups ( $a$ and b), with a relationship ratio of $88.19 \%$. Group a included A-74 and A-98, with a relationship value of $88.89 \%$, while group b included A-122. Sub-clusters 4 included A-136.

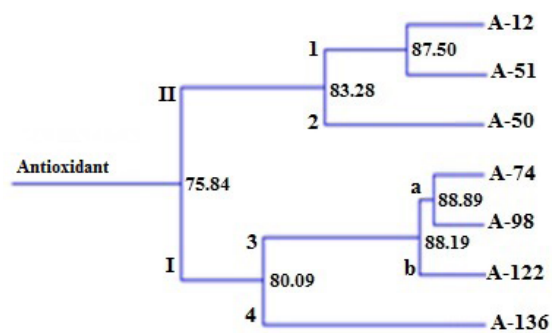

Figure 5. Dendrogram representing the relationship between studied fenugreek accessions determined through UPGMA clustering using simple band matches (tolerance, 3.20\%) based on antioxidant activity data. 


\section{DISCUSSION}

The RAPD technique is a very sensitive method of screening for nucleotide sequence polymorphisms that are randomly distributed throughout the genome, in both coding and non-coding regions, and repeated or single copy (unique) sequences (Welsh and McClelland, 1991). RAPD analysis revealed distinctive qualitative and quantitative variations among $T$. foenum-graecum accessions in the RAPD banding patterns based on the number of gene products, amplified DNA sizes, band intensities, and appearance or disappearance of DNA bands, leading to high levels of DNA polymorphisms. The number of amplification products may be related to the number and direction of genome sequences complementary to the primer. High levels of polymorphism generated by RAPD are considered to be a better parameter for measuring genetic variation patterns and reflect heritable changes in the nucleotide sequences, both in coding and non-coding regions (Lal et al., 2011). These DNA polymorphisms may result from DNA structural changes within base-pair sequences of DNA between oligonucleotide primer binding sites in the genome during DNA replication or gene expression under genotoxic stresses, such as a nucleotide substitution within a target site, an insertion or deletion of a DNA-fragment within the amplified regions, rearrangements of genomic DNA, or inversions, translocations, and transpositions of genes (Welsh and McClelland, 1991).

DNA polymorphisms among different $T$. foenum-graecum accessions may have resulted from the interaction of DNA with ROS such as hydroxyl radical $(\cdot \mathrm{OH})$ generated by abiotic oxidative stress levels in diverse ecogeographical regions, leading to oxidative DNA damage at both the purine and pyrimidine bases, the deoxyribose backbone, change in gene expression, and abnormal oxidative proteins (Sanghera et al., 2013). These changes are exhibited as the loss or deletion of DNA bands (polymorphic) that may be very valuable for DNA fingerprinting and examining genetic variations among different accessions or insertions of the amplified DNA bands (unique) or changes of nitrogenous base or changes in fragment size, and consequently different DNA lengths with highly polymorphism levels. Sundaram and Purwar (2011) showed that RAPD markers are useful for evaluating genetic diversity and relationships among different Trigonella species. Harish et al. (2011) used 5 primers for RAPD analysis to estimate genetic variability among 10 accessions of $T$. foenum-graecum and produced 36 bands with an average of 3.6 bands per primer. They observed intraspecific polymorphisms in banding patterns and concluded that RAPD markers are evaluating genetic variations and assessing phylogenetic relationships in T. foenum-graecum. Cluster analysis revealed considerable variation among different accession of this plant, which may be used for crop improvement through hybridization and marker-assisted selection. The current study demonstrated the potential of RAPD techniques for studying the level and partitioning of genetic variations among different fenugreek accessions.

Because isozymes are direct gene products that show differences in protein-coding genes and produced by different gene loci or by different alleles at the same locus, the banding patterns (zymograms) generated can be effectively correlated to the genetic make-up of the fenugreek sample, which agrees with the results of Karaca (2013). Isozymic analyses of different fenugreek accessions confirmed their heterozygous nature as shown by the more complicated banding pattern with multiple expressions at the same region (heteromeric bands). This may be explained by the presence of multilocus isozyme forms from gene duplication through mutation, polyploidization, and chromosomal aberrations (Karaca, 2013), which may have been caused by ROS inducing environmental genotoxic stresses in their geographic re- 
gions. The isozyme electrophoretic banding profiles generated by GOT and ACP revealed multiple bands on different loci with different $R_{f}$ values and unequal intensities. The $R_{f}$ value of each respective band for schematic isozyme patterns was determined to compare various fenugreek accessions. The different electrophoretic mobilities of zymograms resulted from the different sizes and shapes of enzyme molecules; therefore, their variations indicate genetic variation (Majumder et al., 2012). The high polymorphism levels generated by the 2 isozymes may increase with geographic variation in fenugreek accessions and may be used to measure genetic variability. If an amino acid substitution occurs in a protein molecule, net charge may be altered or conformational changes in isozymes may occur, consequently altering the migration rate of proteins in an electric field, as well as their electrophoretic mobilities as well as catalytic efficiency and stability (Karaca, 2013).

Amino acids analysis by HPLC showed variation in the amount of free amino acids among fenugreek seeds, reflecting the environmental oxidative stress of each ecogeographical region studied. Total EAA content was higher than NEAA content; therefore, fenugreek seeds are a valuable resource for medicine and food containing considerable amount of important proteins, primarily including EAAs. These results agree with those of Uransanaa et al. (2003). The present study identified 16 amino acids among T. foenumgraecum seeds, 9 of which are essential in humans, while Shang et al. (1998) identified 17 amino acids, 7 of which are essential. Changes in amino acid content can alter DNA gene expression, protein synthesis, isozyme activity, and redox-homeostasis. Variations in amino acid content among different accessions may stem from biosynthesis and degradation pathways of environmental oxidative stressinduced proteins, which vary by geographic region. Proteins may undergo a loss of activity or be denatured, and often excess levels of ROS are produced, leading to oxidative damage (Krasensky and Jonak, 2012). Quantitative variations in amino acids among T. foenumgraecum seeds may be interpreted based on oxidative proteins generated by ROS (mainly ${ }^{\circ} \mathrm{OH}$ ), involving oxidation of amino acid chains and generating stable and reactive products such as protein hydro-peroxides, resulting in protein fragmentation. The side chains of all the amino acid residues, particularly cysteine and methionine, are susceptible to oxidation by the action of ROS (Sanghera et al., 2013).

Free radical scavengers may directly react with and quench peroxide radicals to terminate the peroxidation chain reaction and improve the quality and stability of food products (Ravindran et al., 2012). Increasing amino acid content had positive effects on secondary metabolite content, antioxidants, and antioxidant activity (Ardebili et al., 2012). In contrast, the decrease in flavonoid content for a particular accession may be explained based on the negative effect of amino acids, which agrees with the results of Omer et al. (2013). Moreover, plants with high levels of antioxidants, either constitutive or induced, adequately resist oxidative damage (Ravindran et al., 2012). Bukhari et al. (2008) concluded that fenugreek is a good source of natural antioxidant substances such as flavonoids and phenolic acids and contains high levels of antioxidant enzymes and oxygen radical scavenging activities, which can delay or inhibit the oxidation of proteins and DNA or other macromolecules by inhibiting the initiation or propagation of oxidizing chain reactions.

In this study, we observed an increase in amplified DNA products, zymograms, and free amino acids content for fenugreek A-50, which was higher than values for the other 6 accessions studied. This increase may be because of the polyploidazition of genetic materials or chromosomal numbers of fenugreek under abiotic stress at its ecogeographical region. This polyploidazition led to an increase in nitrogenous base sequences in DNA and consequently 
an increase in amplified DNA products, zymograms, and free amino acids content, which was correlated with increasing antioxidant parameters in this germplasm accession to protect the plant from ROS.

In conclusion, wild T. foenum-graecum is a valuable genetic resource showing high antioxidant activity. Genotype accessions based on molecular and biochemical analyses combined with antioxidant activity will play an important role in fenugreek breeding and improvement programs. This is the first report in T. foenum-graecum demonstrating a correlation. RAPD (a DNA marker) and isozymes (a protein marker) yielded similarly high estimates of genetic polymorphisms and supported RAPD as a reliable estimation of genetic variability among fenugreek accessions under their natural environmental stresses, influencing crops strategies. The clustering based on the antioxidant activity data can be correlated with that based on RAPD, isozymes data, and variable amino acids content among the fenugreek accessions. However, the genetic relationships resulting from cluster analyses using data based on RAPD or isozymes analyses indicated that these 2 marker techniques were nearly equivalent, but not identical.

\section{ACKNOWLEDGMENTS}

The authors would like to extend their sincere appreciation to the Deanship of Scientific Research at King Saud University for its funding of this research through the Research Group Project \#RGP-VPP-231. We also would like to thank Prof. Turki Al-Turki King Abdulaziz City for Science and Technology, Riyadh, Saudi Arabia, for providing the fenugreek seeds.

\section{REFERENCES}

Aly AAH, Hussein EM, Omar MR and Abd-Elsalam KA (2011). Effect of amino acid content on the level of cotton seed colonization by mycoflora. Int. J. Agric. Biol. 13: 71-76.

Ardebili ZO, Mohamad ARL, Ardebili NO and Pashaie AR (2012). The induced physiological changes by foliar application of amino acids in Aloe vera L. plants. Plant Omics J. 5: 279-284.

Ayala-Zavala JF, Silva-Espinoza BA, Cruz-Valenzuela MR, Villegas-Ochoa MA, et al. (2012). Antioxidant and antifungal potential of methanol extracts of Phellinus spp. from Sonora, Mexico. Rev. Iberoam. Micol. 29: 132-138.

Bukhari SB, Bhanger MI and Memon S (2008). Antioxidative activity of extracts from fenugreek seeds (Trigonella foenum-graecum). Pak. J. Anal. Environ. Chem. 9: 78-83.

Dangi RS, Lagu MD, Choudhary LB, Ranjekarand PK, et al. (2004). Assessment of genetic diversity in Trigonella foenum-graecum and Trigonella caerulea using ISSR and RAPD markers. BMC Plant Biol. 4: 13.

Dibyendu T (2010). Allozyme variations in leaf esterase and root peroxidase isozymes and linkage with dwarfing genes in induced dwarf mutants of grass pea (Lathyrus sativus L.). Int. J. Genet. Mol. Biol. 2: 112-120.

Gil MI, Thomas BFA, Hess-Pierce B, Hplcroft DM, et al. (2000). Antioxidant activity of pomegranate juice and its relationship with phenolic composition and processing. J. Agric. Food Chem. 48: 4581-4589.

Gonçalves LSA, Rodrigues R, Sudré CP, Bento CS, et al. (2008). Divergência genética em tomate estimada por marcadores RAPD em comparação com descritores multicategóricos. Hortic. Bras. 26: 364-370.

Harish, Gupta AK, Ram K, Singh B, et al. (2011). Molecular and biochemical characterization of different accessions of fenugreek (Trigonella foenum-graecum L.). Libyan Agric. Res. Cent. J. Int. 12: 150-154.

Hojilla-Evangelista MP and Evangelista RL (2006). Effects of cooking and screw-pressing on functional properties of Cuphea PSR23 seed proteins. J. Am. Oil Chem. Soc. 83: 713-718.

Jha SK and Srivastava SK (2012). Determination of antioxidant activity of Trigonella foenum-graecum Linn. in mice. Ann. Phytomedic. 1: 69-74.

Karaca M (2013). Isozymes as biochemical markers in plant genetics. Int. J. Agric. Sci. 3: 851-861.

Kit YS and Chandran S (2010). A simple, rapid and efficient method of isolating DNA from Chokanan mango (Mangifera indica L.). Afr. J. Biotechnol. 9: 5805-5808. 
Krasensky J and Jonak C (2012). Drought, salt, and temperature stress-induced metabolic rearrangements and regulatory networks. J. Exp. Bot. 63: 1593-1608.

Kumar P, Gupta VK, Misra AK, Modi DR, et al. (2009). Potential of molecular markers in plant biotechnology. Plant Omics J. 2: 141-162.

Lal S, Mistry KN, Shah SD, Thaker R, et al. (2011). Genetic diversity assessment in nine cultivars of Catharanthus roseus from Central Gujarat (India) through RAPD, ISSR and SSR markers. J. Res. Biol. 1: 667-675.

Lim SN, Cheung PCK, Ooi VE and Ang PO (2002). Evaluation of antioxidative activity of extracts from brown seaweed, Sargassum siliquastrum. J. Agric. Food Chem. 50: 3862-3866.

Majumder DAN, Hassan L, Rahim MA and Kabir MA (2012). Analysis of genetic diversity in mango (Mangifera indica L.) using isozymetic polymorphism. Afr. J. Biotechnol. 11: 15310-15323.

Miller MJ, Sadowska-Krowicka H, Chotinaruemol S, Kakkis JL, et al. (1993). Amelioration of chronic ileitis by nitric oxide synthase inhibition. J. Pharm. Exp. Ther. 264: 11-16.

Mondini L, Noorani A and Pagnotta MA (2009). Assessing plant genetic diversity by molecular tools. Diversity 1: 19-35.

Omer EA, Said-Al Ahl HAH, El-Gendy AG, Shaban KA, et al. (2013). Effect of amino acids application on production, volatile oil and chemical composition of chamomile cultivated in saline soil at Sinai. J. App. Sci. Res. 9: 3006-3021.

Pasteur N, Pasyeur G, Bonhomme F, Catalan J, et al. (1988). Genetic interpretation of gels, 31-48. In: Practical Isozyme Genetics. John Wiley and Sons, Ellis Horwood.

Pirman T, Stibilj V, Stekar JMA and Combe E (2001). Amino acid composition of beans and lentil. Zb. Biotechnol. Fak. Univ. Ljubl. Kmet. Zootechnol. 781: 57-68.

Ravindran C and Naveenan T (2011). Adaptation of marine derived fungus Chaetomium globosum (NIOCC 36) to alkaline stress using antioxidant properties. Process Biochem. 46: 847-857.

Ravindran C, Naveenan T, Varatharajan GR, Rajasabapathy R, et al. (2012) Antioxidants in mangrove plants and endophytic fungal associations. Bot. Marina 55: 269-279.

Sadder MT and Ateyyeh AF (2006). Molecular assessment of polymorphism among local Jordanian genotypes of the common fig (Ficus carica L.). Sci. Hortic. 107: 347-351.

Sanghera GS, Malhotra PK, Sidhu GS, Sharma VK, et al. (2013). Genetic engineering of crop plants for enhanced antioxidants activity. Int. J. Adv. Res. Tech. 2: 428- 458.

Saxena SN, Karwa S, Saxena R, Sharma T, et al. (2011). Analysis of antioxidant activity, phenolic and flavonoid content of fenugreek (Trigonella foenum-graecum L.) seed extracts. Int. J. Seed Spices 1: 38-43.

Shang M, Cai S and Wang X (1998). Analysis of amino acids in Trigonella foenumgraecum seeds. Zhong Yao Cai 21: 188-90.

Sheikhlar A (2013). Trigonella foenum-graecum L. (fenugreek) as a medicinal herb in animals growth and health. Sci. Int. 1: 194-198.

Shinde VM, Dhalwal K, Mahadik KR, Joshi KS, et al. (2007). RAPD analysis for determination of components in herbal medicine. eCAM 4: 21-23.

Sliwinska E, Pisarczyk I, Pawlik A and Galbraith DW (2009). Measuring genome size of desert plants using dry seeds. Botany 87: 127-135.

Soltis DE, Haufler CH, Darrow DC and Gastony GJ (1983). Starch gel electrophoresis of ferns: A compilation of grinding buffers, gel and electrode buffers and staining schedules. Am. Fern. J. 73: 9-27.

Sundaram S and Purwar S (2011). Assessment of genetic diversity among fenugreek (Trigonella foenum-graecum L.) using RAPD molecular markers. J. Med. Plants Res. 5: 1543-1548.

Uransanaa M, Gerel D, Jamyansan Y and Dash T (2003). Protein and amino acid composition of sea buckthorn seeds (Hippophae rhamnoides mongolica Rouse). Mongolian J. Biol. Sci. 1: 85-88.

Welsh J and McClelland M (1991). Genomic fingerprinting using arbitrarily primed PCR and a matrix of pairwise combinations of primers. Nucleic Acids Res. 19: 5275-5279.

Williams JGK, Kubelic AR, Livak KJ, Rafalski JA, et al. (1990). DNA polymorphisms amplified by arbitrary primers are useful as genetic markers. Nucleic Acids Res. 18: 6531-6535.

Wilson K and Walker J (2005). Principles and Techniques of Biochemistry and Molecular Biology. Cambridge University Press, Cambridge.

Zhishen J, Mengcheng T and Jianming W (1999). The determination of flavonoids content in mulberry and their scavenging effects on superoxide radicals. Food Chem. 64: 555-559. 